\title{
How Can We Obtain Tissue from a Subepithelial Lesion for Pathologic Diagnosis?
}

\author{
Eun Young Kim \\ Department of Internal Medicine, Catholic University of Daegu School of Medicine, Daegu, Korea
}

See "Mucosal Incision and Forceps Biopsy for Reliable Tissue Sampling of Gastric Subepithelial Tumors" by Sa Young Shin, Sang Jin Lee, Jae Hyuck Jun, et al., on page 64-68.

Currently, endoscopic ultrasonography (EUS) is the best available tool for evaluation of a subepithelial lesion (SEL). However, imaging study alone with EUS does not always provide an accurate diagnosis. ${ }^{1}$ If the information provided by EUS on the echogenicity and originating layer of SEL is not typical for an "educated guess," patients may become anxious because of the uncertainty of the diagnosis. In that situation, the endoscopist should try to obtain tissue for definitive pathologic diagnosis of SEL. EUS-guided sampling is the traditional approach, but the diagnostic yield varies widely, depending on factors such as location, size, histological type of lesion, experience of the endosonographer, availability of an on-site cytopathologist, and needle and technique used. ${ }^{2}$

Various alternative methods for tissue sampling from SEL have been reported. Bite-on-bite biopsy using standard forceps (FB-25K-1: Olympus, Tokyo, Japan; jaw volume 5-6 $\mathrm{mm}^{3}$ ), with 2-8 bites per lesion, achieved a 38\% diagnostic yield (14 of 38 lesions). ${ }^{3}$ Blood oozing occurred in $14 \%$ and was treated with diluted epinephrine injection or clipping. ${ }^{3}$ In a large cohort, when bite-on-bite biopsy samples were obtained with jumbo biopsy forceps (RJ-4 Boston Scientific, Inc., Natick,

Received: January 9, 2017 Revised: January 20, 2017

Accepted: January 20, 2017

Correspondence: Eun Young Kim

Department of Internal Medicine, Catholic University of Daegu School of Medicine, 33 Duryugongwon-ro 17-gil, Nam-gu, Daegu 42472, Korea

Tel: +82-53-650-4092, Fax: +82-53-624-3281, E-mail: kimey@cu.ac.kr

(cc) This is an Open Access article distributed under the terms of the Creative Commons Attribution Non-Commercial License (http://creativecommons.org/ licenses/by-nc/3.0) which permits unrestricted non-commercial use, distribution, and reproduction in any medium, provided the original work is properly cited.
MA, USA; jaw volume $12-13 \mathrm{~mm}^{3}$ ) in 129 patients with SEL, the median sample size was $12.5 \mathrm{~mm}$ (range $3-50 \mathrm{~mm}$ ), and diagnostic yield was $58.9 \%$. ${ }^{4}$ Significant bleeding requiring endoscopic hemostasis occurred in $35.7 \%$, and admission was needed in $3.1 \%$.

More aggressive endoscopic techniques have been used to acquire tissue samples. Lee et al. ${ }^{5}$ described "endoscopic partial resection with unroofing" to get tissue from SEL. After EUS, they first removed mucosa overlying the SEL with a snare to expose the tumor. Then, they partially resected the exposed tumor with the snare. The median size of lesions was $16.3 \mathrm{~mm}$ (range 11.4-25.0 mm). Definitive diagnosis was made in 15 of 16 cases. Blood oozing was frequently noted from the cut surface during the procedure, but was easily controlled by argon plasma coagulation (APC). Dolak et al. ${ }^{6}$ recently reported a retrospective study of endoscopic unroofing for small gastric SELs. After EUS examination, they partially resected the SEL together with covering mucosa in one step, with a single-use polypectomy snare. The mean diameter of SELs was $26 \pm 13$ $\mathrm{mm}$ (range 10-60 mm). Tissue acquisition was possible in 13 of 14 cases. The mean diameter of obtained tissues including covering mucosa was $23 \pm 10 \mathrm{~mm}$ (range $7-40 \mathrm{~mm}$ ). This access yielded a histologic diagnosis in 12 of 13 cases. Bleeding occurred in 4 cases during the procedure, and all were managed with clipping and/or APC.

In this issue of Clinical Endoscopy, Shin et al. ${ }^{7}$ reported the results of "mucosal incision and forcep biopsy for SEL." After submucosal injection of glycerol solution mixed with indigo carmine, they made a $10-\mathrm{mm}$ linear incision with a hook knife on the top of the mucosa covering the SEL. After 
exposing SEL through the incision site, forcep biopsy was performed. After biopsy (median 8 pieces), the incision site was closed with clips. Definitive pathologic diagnosis was possible in 11 of 12 cases without major complications. All procedures were done on an inpatient basis. A similar technique was previously proposed by de la Serna-Higuera et al. ${ }^{8}$ They described an "EUS-guided single-incision with needle knife (SINK) and deep forcep biopsy" procedure. They first performed EUS examination of SEL and made a 6-12-mm linear incision over the highest convexity zone of the lesion with a conventional needle-knife sphincterotome. The biopsy forcep was introduced deeply through the incision to obtain 3 to 5 samples. The incision site was also closed with endoclips. Pathologic diagnosis was possible in 13 of 14 patients. Among 8 gastrointestinal stromal tumors, immunohistochemical staining was possible in 7 cases. Analysis of malignant potential was feasible in 5 cases. Another method named "bloc biopsy by submucosal endoscopy with a mucosal flap" is slightly different from SINK. ${ }^{9}$ After creating a $10-\mathrm{mm}$ incision near the margin of the SEL, they approached the mass through a tunnel from the incision site by submucosal dissection. Using submucosal endoscopy beneath the mucosal flap, they excised part of the visible SEL by harvesting a $5 \times 5 \times 2 \mathrm{~mm}$ block specimen with a needle-knife. The detached surface was closed with clips after the procedure. Pathological diagnosis was attainable in all 8 patients without serious complications. The procedure time was about 50 minutes.

Other researchers implemented more invasive endoscopic procedures to remove the entire SEL endoscopically for simultaneous diagnosis and therapy. Binmoeller et al. ${ }^{10}$ introduced "suck-ligate-unroof-biopsy (SLUB)" for small SELs less than $20 \mathrm{~mm}$ in diameter on EUS examination. They tightly ligated the base of a SEL with a 20-mm loop placed along the outer rim of an 18-mm oblique transparent cap mounted on the tip of a therapeutic endoscope. Then, they made two perpendicular incisions over the covering mucosa with a needle-knife to unroof the SEL. A tissue specimen was obtained from the exposed lesion using standard forceps. The mean diameter of the SELs was $10 \mathrm{~mm}$ (range 6-15 mm). Histologic diagnosis was possible in all 24 SELs without bleeding or perforation. On follow up endoscopy and EUS, no residual lesion was noted due to spontaneous sloughing elicited by ischemic necrosis after ligation. For SELs larger than $20 \mathrm{~mm}$, they used "retract-ligate-unroof-biopsy" technique. ${ }^{11}$ Using a double-channel endoscope, they simultaneously retracted and ligated the SEL with a 3-pronged anchoring device/rat-tooth forcep and endoloop. Incision and biopsy were performed as for SLUB. The procedure was successful in 13 of 16 cases. Two cases had delayed bleeding that required repeated looping. In addition, SEL enucleation by standard or modified submucosal dissec- tion technique, submucosal tunnel dissection, and endoscopic full-thickness resection have also been successfully performed with little risk of complications. ${ }^{12}$

There is still no consensus regarding the method of tissue diagnosis for SEL. Although there are reports using various techniques, the numbers of included cases are relatively small and there are few results of long-term follow-up. When histologic diagnosis of SEL is urgent, an easy, safe, and cost-effective method that yields sufficient tissue for accurate diagnosis is necessary. Continuous data collection on various techniques and their analysis are mandatory for consensus. Further development of needles for EUS-guided sampling and accessories for an endoscope will improve the ability to obtain tissue from SEL.

\section{Conflicts of Interest}

The author has no financial conflicts of interest.

\section{REFERENCES}

1. Kim EY. Diagnosis of subepithelial lesion: still "tissue is the issue". Clin Endosc 2013;46:313-314.

2. Kim EY. Which needle is better for diagnosing subepithelial lesions? Clin Endosc 2015;48:91-93.

3. Ji JS, Lee BI, Choi KY, et al. Diagnostic yield of tissue sampling using a bite-on-bite technique for incidental subepithelial lesions. Korean J Intern Med 2009;24:101-105.

4. Buscaglia JM, Nagula S, Jayaraman V, et al. Diagnostic yield and safety of jumbo biopsy forceps in patients with subepithelial lesions of the upper and lower GI tract. Gastrointest Endosc 2012;75:1147-1152.

5. Lee CK, Chung IK, Lee SH, et al. Endoscopic partial resection with the unroofing technique for reliable tissue diagnosis of upper GI subepithelial tumors originating from the muscularis propria on EUS (with video). Gastrointest Endosc 2010;71:188-194.

6. Dolak W, Beer A, Kristo I, et al. A retrospective study on the safety, diagnostic yield, and therapeutic effects of endoscopic unroofing for small gastric subepithelial tumors. Gastrointest Endosc 2016;84:924-929.

7. Shin SY, Lee SJ, Jun JH, et al. Mucosal incision and forceps biopsy for reliable tissue sampling of gastric subepithelial tumors. Clin Endosc 2017;50:64-68.

8. de la Serna-Higuera C, Pérez-Miranda M, Díez-Redondo P, et al. EUS-guided single-incision needle-knife biopsy: description and results of a new method for tissue sampling of subepithelial GI tumors (with video). Gastrointest Endosc 2011;74:672-676.

9. Kobara H, Mori H, Fujihara S, et al. Bloc biopsy by using submucosal endoscopy with a mucosal flap method for gastric subepithelial tumor tissue sampling (with video). Gastrointest Endosc 2013;77:141-145.

10. Binmoeller KF, Shah JN, Bhat YM, Kane SD. Suck-ligate-unroof-biopsy by using a detachable 20-mm loop for the diagnosis and therapy of small subepithelial tumors (with video). Gastrointest Endosc 2014;79:750-755.

11. Binmoeller KF, Shah JN, Bhat YM, Kane SD. Retract-ligate-unroof-biopsy: a novel approach to the diagnosis and therapy of large nonpedunculated stromal tumors (with video). Gastrointest Endosc 2013;77:803808.

12. Kim SY, Kim KO. Management of gastric subepithelial tumors: The role of endoscopy. World J Gastrointest Endosc 2016;8:418-424. 